\title{
ANALISIS KARAKTER ANTAGONIS UTAMA PADA SINETRON "CINTA DAN RAHASIA SEASON 1" DI NET.TV VERSI VLADIMIR PROPP
}

\author{
Inmas Jakfar Abdillah \\ Siti Maemunah \\ Raden Roro Ari Prasetyowati \\ Jurusan Film \& Televisi, Fakultas Seni Media Rekam, Institut Seni Indonesia Yogyakarta \\ J1. Parangtritis km. 6.5 Yogyakarta Telp. (0274) 381047
}

\begin{abstract}
ABSTRAK
Sinetron "Cinta dan Rahasia" memiliki kelogisan fungsi karakter antagonis. Tindakan yang dilakukan terhadap protagonis tidak hanya dominan bentuk tindakan negatif namun tindakan positif juga dilakukan. Peran antagonis saat menghambat protagonis tidak dilihat dari kedudukan moral atau sifatnya, namun hubungan kedua karakter menimbulkan konflik. Skripsi karya tulis berjudul Analisis Karakter Antagonis Utama Pada Sinetron "Cinta dan Rahasia Season 1" di NET. Versi Vladimir Propp ini, tujuan penelitiannya adalah menemukan fungsi karakter antagonis utama terhadap karakter protagonis versi Vladimir Propp, dan mengetahui tindakan karakter antagonis utama melakukan tindakan positif serta negatif terhadap karakter protagonis.

Metode kualitatif dengan pendekatan deskriptif dan didukung dengan metode kuantitatif merupakan metode yang digunakan. Menentukan karakter antagonis utama yang akan dibedah dengan mendeskripsikan fungsi karakter antagonis dengan menggunakan teori Vladimir Propp, kemudian dilakukan analisis. Untuk mengetahui tindakan karakter antagonis terhadap protagonis yang masih bersifat positif atau negatif, menggunakan metode kuantitatif untuk menguji teknik mengumpulan data yang disajikan dengan menggunakan tabel. Pengecekan validitas dari data kuantitatif dengan dilakukan memahami permasalahan, proses terahkir adalah membuat kesimpulan.

Berdasarkan hasil kajian dapat disimpulkan bahwa ditemukan 13 fungsi karakter antagonis terhadap protagonis yaitu Kekerasan $(\delta)$, Pengintaian (E), Pengiriman $(\varsigma)$, Tipu daya $(\eta)$, Keterlibatan $(\Theta)$, Kejahatan/ Kekuranagan (A), Mediasi (B), Tindakan balasan (C), Perjuangan (H), Kemenangan (I), Pengejaran (Pr), Pemaparan (Ex), Hukuman (U). Tindakan tersebut mempunyai alasan dan tujuan yang mendorong untuk berbuat. Pembuatan tokoh antagonis utama pada Gita dibuat sesuai logika dalam keadaan yang terjadi dalam cerita "Cinta dan Rahasia season 1". Bukti kelogisan karakter antagonis utama dapat ditemukan bahwa tindakan yang dilakukan mengandung nilai negatif dan juga positif. Tindakan negatif lebih banyak dilakukan namun tindakan positif juga hampir sama banyaknya. Tindakan negatif sebesar 58\% dan tindakan positif sebesar 37\%. Tindakan positif sangat signifikan menunjukan bahwa karakter antagonis tidak selamanya hanya menunjukan sisi negatifnya, namun seperti halnya karakter manusia yang memiliki sisi positif juga perlu ditunjukan.
\end{abstract}

kata kunci : karakter, fungsi, tindakan

\section{Pendahuluan}

Antagonis sering dikaitkan dengan tokoh penjahat dalam pengertian yang sebenarnya, misalnya pembunuh, perampok dan pencuri, sebagaimana yang ditunjukan antara lain pada film Rio 
Inmas JakfarAbdillah, Siti Maemunah, Raden Roro Ari Prasetyowati,

(2011), The Adventures of Tin Tin (2011), dan Anthony Zimmer (2005).

Tokoh polisi, ibu, guru atau bahkan anak kecil juga dapat dijadikan sebagai antagonis. Antagonis tidak selalu harus berupa tokoh dengan sosok kekar penuh tato dengan ekspresi wajah yang sangar. Antagonis dapat berupa gadis cantik atau pemuda tampan, orang tua yang rapuh, atau tokoh penuh sopan santun dengan espresi wajah yang lugu.

Fenomena karakter antagonis pada sinetron di Indonesia menjadi daya tarik tersendiri dalam cerita. Banyak persepsi bahwa antagonis pasti berperan yang mewakili hal-hal yang bersifat negatif, penganggu, jahat, melakukan tindakan tidak baik. Karakter protagonist selalu berperan mewakili tindakan hanya diperlihatkan sisi positif saja. Pada pembuatan karakter antagonis dan protagonis terlihat hanya dibuat dari sifat moral karakter tersebut tanpa mempertimbangkan hubungan antar tokoh dalam peristiwa sebenarnya. Karakter antagonis yang selalu menunjukan sikap negatif agar cerita tersebut menarik dan dapat mengahadirkan pergolakan konflik setiap tokoh.

Pada objek yang akan diteliti adalah sinetron "Cinta dan Rahasia season 1" di NET. pada karakter antagonis berbeda, dari karakter antagonis sinetron-sinetron lain saat menghalangi protagonis hanya bertindak negatif saja. Objek ini menarik untuk diteliti karena kelogisan fungsi karakter antagonis melakukan tindakan terhadap protagonis tidak hanya dominan bentuk tindakan negatif namun tindakan positif juga dilakukan. Peran antagonis di sinetron "Cinta dan Rahasia" saat menghambat protagonis tidak dilihat dari kedudukan moral atau sifatnya namun hubungan kedua karakter menimbulkan konflik. Hubungan antara protagonis dan antagonis memunculkan bentuk tindakan yang bermacam-macam khususnya pada karakter antagonis.

Penelitian tugas akhir ini lebih menganalisis fungsi karakter antagonis utama dalam sinetron. Fokus ini dipilih karena pembuktian teori fungsi karakter dalam narasi Vladimir Propp dan memberikan refrensi bagi penelitian lain sebagai acuan pengembangan penelitian selanjutnya. Bentuk tindakan apa saja yang dilakukan antagonis utama. Nantinya akan diketahui tindakan karakter antagonis dalam menghambat protagonis apakah masih banyak melakukan tindakan positif atau negatif.

Objek peneliti ini layak diteliti karena sinetron "Cinta dan Rahasia" tayang di NET. adalah salah satu stasiun menayangkan progam-progam berkualitas. Maraknya sejumlah stasiun televisi dalam perlombaan penayangan sinetron, $\mathrm{PH}$ memproduksi sinetron saat 
ini diciptakan iklim kompetisi cepat saji. Tanpa riset audiens dan kajian budaya sinetron diproduksi dengan logika yang sangat pendek. Berbeda pada tayangan sinetron dibuat oleh NET. sebuah tayangan tampil berbeda dari segi pembuatan cerita dengan hubungan antar karakter-karakter yang dipikirkan sesuai dengan logika pada story.

Penelitian ini diharapkan dapat memberikan wawasan bagi mahasiswa, mengenai bentuk fungsi dan tindakan yang dilakukan oleh karakter antagonis utama saat menghambat protagonis pada sinetron. Manfaat lain memberikan perkembangan ilmu pengetahuan berupa konsep dan teori, khususnya pada analis fungsi karakter di sinetron "Cinta dan Rahasia". Hasil penelitian yang ditemukan dapat menjadi pembuktian teori yang sudah ada, bahkan dapat menjadi temuan baru apabila hasil penelitian membuktikan, bahwa teori yang digunakan belum tentu benar. Selain itu penelitian ini diharapkan mampu menjadi pertimbangan perencanaan bagi dan perbaikan bagi penulis naskah dalam membuat karakter antagonis. Perbaikan tersebut bisa dilihat dari kelogisan tindakan yang dilakukan terhadap hubungan tokoh lain. Memberikan referensi bagi penelitian lain sebagai acuan pengembangan penelitian selanjutnya, pada objek penelitian dalam ruang lingkup yang lebih luas. Jumlah objek penelitian tidak hanya satu stasiun televisi tapi seluruh stasiun televisi di Indonesia.

Proses penelitian ini ialah dengan menentukan karakter antagonis utama, yang nantinya akan dibedah dengan mendeskripsikan fungsi karakter antagonis dengan menggunakan teori Vladimir Propp. Penelitian ini menggunakan sampel sebanyak 18 epsiode, yaitu ciri episode yang dipilih sesuai yang sudah ditentukan yaitu hubungan karakter antagonis utama terhadap karakter protagonis. Selanjutnya dilakukan proses kualitatif dengan menganalisis setiap fungsi karakter antagonis utama terhadap protagonis. Kemudian untuk mengetahui tindakan karakter antagonis terhadap protagonis yang masih bersifat positif atau negatif, menggunakan metode kuantitatif berfungsi menguji teknik mengumpulan data yang disajikan dengan menggunakan tabel berisi tindakan-tindakan karakter antagonis utama. Setelah mengetahui jumlah tindakan yang ditemukan, melakukan perhitungan untuk menemukan persentase yang dilakukan antara tindakan positif dan negatif. Dapat diketahui jawaban yang akurat untuk memperkuat dan mengecek validitas dari data kuantitatif maka dilakukan memahami permasalahan tersebut. 
Inmas JakfarAbdillah, Siti Maemunah, Raden Roro Ari Prasetyowati,

\section{Pembahasan}

A. Analisis fungsi karakter antagonis utama pada sinetron "Cinta dan Rahasia season 1" di Net. TV Versi Vladimir Propp

Dari hasil penelitian pada sinetron "Cinta dan Rahasia season 1" telah ditemukan sebanyak 13 fungsi yang dilakukan oleh antagonis utama (Gita) terhadap protagonis (Rizky dan Nadine) dengan mempertimbangkan sampel sebanyak 18 epsiode. Tidak semua episode dalam cerita memiliki 13 Fungsi tersebut, maka sampel yang temukan disesuaikan dengan kriteria yang sudah ditentukan. Berikut fungsi 13 Fungsi yang ditemukan dalam 18 sampel. Menurut Propp, sebuah cerita biasanya dimulai sebuah awal yaitu ketika seorang keluarga diperkenalkan. Walaupun situasi ini bukan merupakan suatu fungsi, namun situasi ini merupakan unsur morfologi yang terpenting (Eriyanto 2013, 66) situasi awal diikuti dengan fungsi-fungsi, antara lain sebagai berikut.

Fungsi situasi Awal dengan simbol "A" adalah pengawalan sebuah cerita yang menceritakan awal mula persahabatan antara Rizky, Nadine, dan Gita sudah terjalin waktu kecil. Definisi fungsi situasi awal menurut Propp adalah Anggota keluarga atau sosok pahlawan diperkenalkan. Pahlawan sering kali digambarkan sebagai orang biasa. (Eriyanto 2013, 66). Fungsi ini juga tidak menunjukan bermacam-macam kejadian pada para tokoh namun hanya menunjukan situasi awal yang tidak terjadi apa-apa.

\section{Fungsi Kekerasan $(\delta)$}

Fungsi Kekerasan adalah Pahlawan melanggar larangan. Ini umumnya menjadi pintu masuk hadirnya penjahat ke dalam cerita, meskipun tidak selalu menghadapi pahlawan (Eriyanto 2013, $67)$.

Tabel 1. Fungsi Kekerasan Gita meyalahkan Nadine episode 56

\begin{tabular}{ccc}
\hline & & Screen Shot \\
\hline Simbol & Fungsi & $4: 56$ \\
\hline$\Delta$ & Kekerasan & $\begin{array}{l}\text { Gita mengetahui Nadine tidak jujur dengan perasaan cintanya } \\
\text { pada Rizky. Gita menyalahkan Nadine karena membuat kecewa } \\
\text { dirinya dan membuat sakit hati banyak orang. }\end{array}$ \\
\hline
\end{tabular}


Tindakan menyalahkan yang dilakukan Gita adalah bentuk marah dan kecewa terhadap Nadine. Apabila seseorang mengalami marah (emosi), maka kemarahan tersebut tidak segera hilang begitu saja, tetapi masih terus berlangsung dalam jiwa diri orang bersangkutan (Walgito 2005, 223). Gita menyalahkan Nadine, kesalahan tersebut membuat orang sekitar mereka menjadi patah hati. Episode 56 juga menjadi bentuk perubahan sikap negatif Gita terhadap Nadine dan Rizky sampai dengan episode ke 59.
2. Fungsi Pengintaian (simbol " $\delta ")$

Pengintaian menurut Propp adalah Penjahat membuat sebuah upaya pengintaian. Penjahat kerap kali menyamar, sebagai cara mencari informasi yang berharga (Eriyanto 2013, 67). Fungsi pengintaian yang dilakukan oleh Gita muncul dalam 4 episode yaitu di episode 13, 28, 30 dan 50, Episode 30.

Tabel 2. Fungsi Pengintaian Gita melihat kedekatan Nadine dan Rizky episode 30

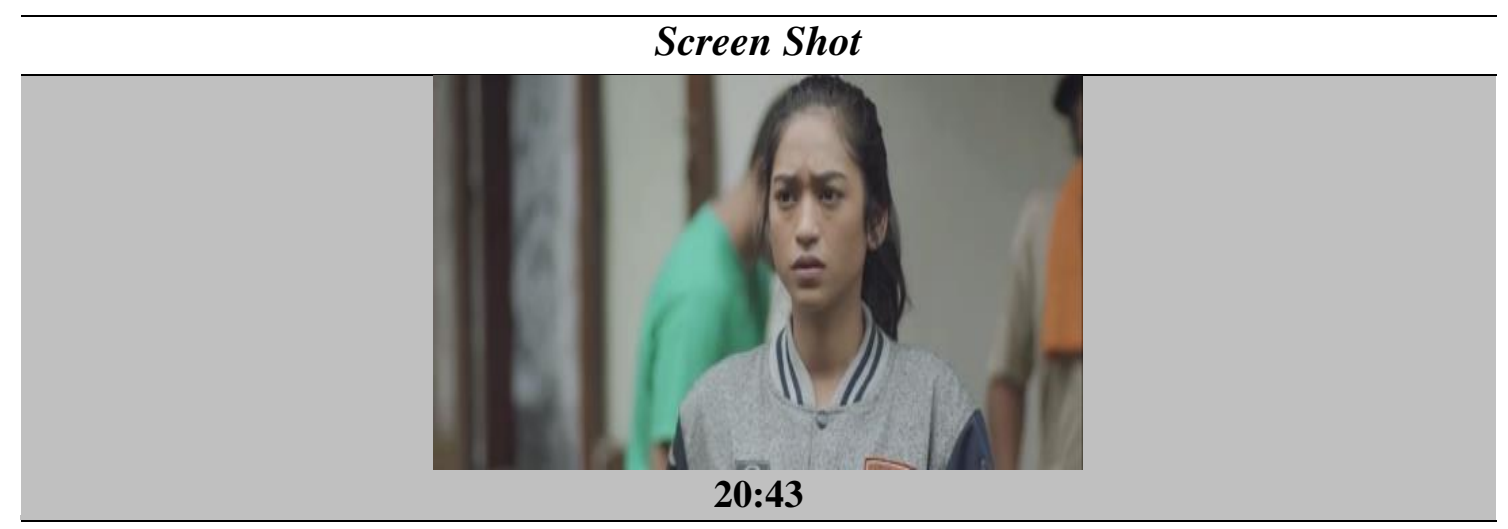

Simbol Fungsi Deskripsi Fungsi

E Pengintaian Gita melihat kedekatan Nadine dan Rizky, hatinya sangat sakit.

Upaya pengintaian lain yaitu pada episode 30. Tindakan pengintaian dilakukan, setelah Gita mengetahui bahwa Rizky mencintai Nadine pada episode24. Episode 25 adalah awal perubahan sikap Gita terhadap Rizky dan Nadine, seperti dalam fungsi pengintaian.

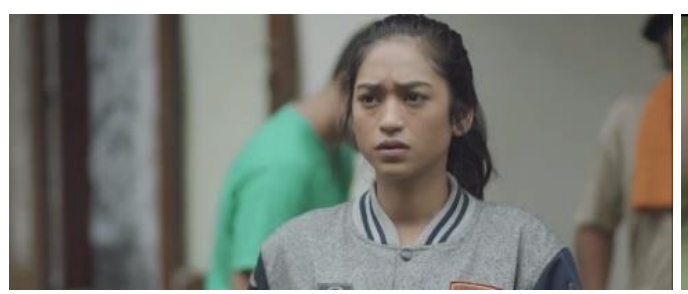

Gambar 1 Screen Shot 20:32

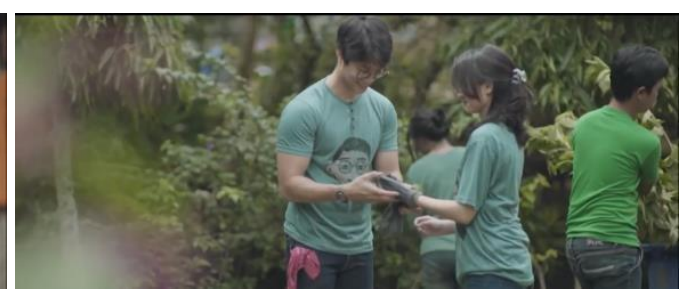

Gambar 2 Screen Shot 20:43

"Cinta dan Rahasia season 1" eps. 30 
Inmas JakfarAbdillah, Siti Maemunah, Raden Roro Ari Prasetyowati,

Gita melihat kedekatan Rizky dan Nadine terlihat ekspresi sedih dan memendam kesedihan. Episode 30 Gita mulai lebih peka melihat kedekatan Rizky dan Nadine, kemudian berdampak pada sakit hati yang dipendam dalam hatinya menimbulkan perasaan menyakiti diri sendiri. Karakter protagonis Rizky dan Nadine posisinya tidak mengetahui bahwa Gita sedang cemburu, karena dari awal Gita tidak jujur dengan perasaanya terhadap Rizky.

Fungsi pengintaian yang ditemukan juga membuktikan Gita sebagai karakter antagonis dalam cerita. Menurut Budiman Akbar dalam bukunya berjudul "Semua Bisa Menulis Skenario Panduan teknik menulis skenario untuk film dan sinetron" mengatakan,

"Penentuan karakter yang menjadi peran Antagonis tidak dilihat dari kedudukan moral, sifat, dan sikapnya, melainkan dari hubungan kerakter tersebut dengan karakter protagonis. Pada sebagian besar cerita ada, karakter antagonis adalah penyebab tindakan dan peristiwa yang terjadi dalam sebuah film" (Akbar 2015, 49).

Gita ada tokoh awal mula terjadinya sebuah konflik antar tokoh utama. Gita melakukan perasaan menyakiti diri sendiri dengan memendam perasaan pada Rizky dan tidak jujur mengutarakannya. Hubungan persahabatan Gita dengan Rizky dan
Nadine mulai berubah mengarah pada tindakan Gita yang lebih cemburu.

\section{Fungsi Tipu Daya ( $\eta)$}

Definisi fungsi Tipu Daya adalah Penjahat berusaha menipu korbannya. Penjahat mencoba menipu korban untuk menguasai korban atau barang-barang korban. Para penjahat menggunakan berbagai cara untuk menipu pahlawan atau korban (Eriyanto 2013, 67).

Fungsi ini merupakan fungsi paling banyak dilakukan oleh Gita. Episode yang ditemukan sebesar 7 episode yang terdiri dari 2, 4, 13, 25, 27, 35 dan 51 episode. Fungsi ini dilakukan Gita sebagian besar adalah membohongi kepada karakter protagonis yaitu Rizky dan Nadine.

\section{Fungsi Keterlibatan $(\Theta)$}

Fungsi Keterlibatan menurut Propp yaitu Korban tertipu, tanpa disadari membantu musuhnya. Korban tertipu oleh penipuan, tanpa disadari membantu musuh. Tipu daya dari penjahat bekerja dan pahlawan atau korban masuk dalam perangkap yang dibuat oleh penjahat. Dalam banyak cerita ini bisa berupa memberikan penjahat suatu informasi yang penting (Eriyanto 2013, 68). Fungsi Keterlibatan ditemukan sebanyak 6 episode yang terdiri dari 14, 25, 27, 34, 44 dan 57 episode. Rizky sebagai korban tanpa disadari tertipu dan membantu penjahat yaitu Gita. 


\section{Fungsi Pengejaran (Pr)}

Fungsi Pengejaran adalah Penjahat melakukan pembalasan, pahlawan dikejar. Penjahat atau pengikut penjahat tidak terima dengan kekalahan. Melakukan pengajaran terhadap pahlawan, merusak nama baik pahlawan (Eriyanto 2013, 70). Fungsi pengejaran menurut Propp lebih pada penjahat mengejar pahlawan, tindakan yang dilakukan bersifat negatif seperti pembalasan dan merusak nama baik. Hal tersebut dapat mewakili gambaran pada karakter penjahat melakukan perilaku negatif dengan pahlawan. Perilaku negatif karena individu menghadapi dua situasi yang dua-duanya negatif, individu tersebut harus mengambil salah satu keadaan untuk dapat menimbulkan konflik (Walgito 2000, 156).

Berbeda pada karakter antagonis dalam cerita "Cinta dan Rahasia" terlihat bahwa Gita memang melakukan pengejaran terhadap Rizky namun tidak melakukan perilaku Negatif.

Fungsi pengejaran pada menit 31:50 Gita sampai datang ke rumah Rizky untuk mengutarakan perasaanya. Tindakan Gita adalah ingin jujur pada Rizky. Fungsi pengejaran ini terlihat pembuatan karakter antagonis melakukan tindakan tidak selamanya negatif. Situasi ini berada dalam kedua objek yang mengandung nilai positif, dari dua objek tersebut individu harus mengambil salah satu (Walgito 2000, 155). Alasan Gita sebelumnya karena mendapatkan saran dari Dimas apabila rahasia Gita jangan terus dipendam maka harus jujur. Dari alasan tersebut karakter Gita memiliki tindakan positif walapun masuk dalam fungsi Pengejaran. Jadi penentuan tindakan oleh antagonis menyesuaikan hubungan antar karakter protagonis harus ada alasan terlebih dahulu. Alasan tersebut nantinya menjadi pilihan untuk bertindak.

Tabel 3. Fungsi Pengejaran Gita datang ke rumah Rizky Episode 12

\section{Screen Shot}

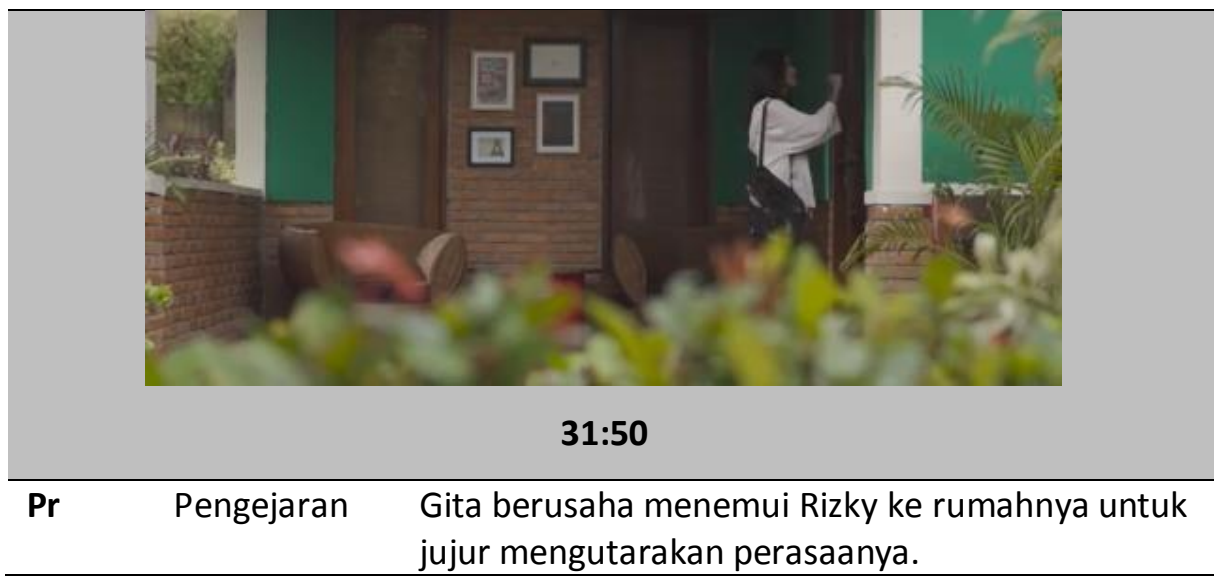


Inmas JakfarAbdillah, Siti Maemunah, Raden Roro Ari Prasetyowati,

6. Fungsi Pemaparan (Ex)

Fungsi Pemaparan adalah Kedok terbuka: penjahat dan pahlawan palsu. Kedok Pahlawan palsu terbuka. Pahlawan palsu menampilkan dirinya sebagai sosok yang jahat (Eriyanto 2013, 67). Kedok kebuka Gita baru muncul di episode 34, dimana pertengahan cerita memunculkan ciri fungsi pemaparan. Tujuan dibuatnya fungsi Pemaparan di pertengahan cerita akan terjadi banyak konflik. Konflik ini bertujuan untuk menciptakan pergolakan batin karakter tokoh atau pergesekan antara karakter tokoh utama (Akbar 2015, 55).

Drama dibangun atas dasar keraguan. Emosi dramatik muncul dari keraguan yang tumbuh dari situasi tanpa kepastian. Sepanjang Film, dibutuhkan hambatan dan konflik untuk mempertahankan keraguan penonton. Tanpa keraguan, tidak ada drama (Armanto dan Marinto 2013, 24). Salah satu konflik yang terjadi yaitu Gita sebagai penghalang hubungan antara Nadine dan Rizky yang saling mencintai. Ketika posisi Gita sudah menjadi penghalang akan melahirkan keraguan. Hambatan yang menghalangi perjalanan kehendak protagonis yaitu Rizky dan Nadine tidak mencapai tujuan untuk bersama dalam sebuah hubungan kekasih. Keraguan yang muncul dari kedua tokoh Protagonis seperti Rizky yang menjadi bimbang untuk memilih antara Nadine atau Gita, Nadine raguragu untuk menerima cinta Rizky yang dapat menyakiti hati Gita.

\section{B. Tindakan positif dan negatif} karakter antagonis utama terhadap karakter protagonis pada sinetron “Cinta dan Rahasia season 1" di NET. TV.

Bentuk dalam tindakan pada tokoh Gita dari 18 sampel, ditemukanlah 19 tindakan utama. Tindakan-tindakan ini mempunyai nilai positif dan negatif. Nilai positif mempunyai segi menguntungkan dan nilai negatif mempunyai unsur-unsur segi merugikan. Di dalam master tabel terdiri dalam 19 Tindakan yaitu Berbohong, Memaafkan, Jujur, Membiarkan, Marah, Menaruh barang secara diam-diam, Gelisah, Acuh tak acuh, Berterima kasih, Menyamarkan, Pura-pura, Keras Kepala, Menolak, Menahan Kesedihan, Mengintai, Mendoakan, Senang, Menyalahkan, dan Egois.

Setiap Kategori memiliki fungsi masing-masing yang kemudian dikelompokkan dari beberapa sub yang sudah dicantumkan dalam tabel nilai positif dan negatif. Tindakan berbohong tidak selamanya memiliki nilai negatif yang merugikan. Nilai positif juga dapat dilakukan dalam tindakan berbohong, namun memiliki alasan dan motivasi untuk melakukan tindakan tersebut. 
Alasan seorang karakter untuk bertindak sebagaimana yang ia lakukan dinamakan motivasi (Stanton 2012, 33).

Tindakan yang dilakukan Gita terhadap Rizky dan Nadine sebagian besar adalah tindakan Negatif sebesar 60\%. Presentase antara tindakan negatif dan positif tidak terlalu jauh yaitu sebesar $40 \%$. Berikut ini contoh bentuk tindakan yang dilakukan seperti tindakan Berbohong.

Tindakan Berbohong dengan nilai positif sebesar $0,07 \%$. Tindakan ini Gita melakukan adegan untuk berbuat, dilihat dari hasrat dan maksud mendorong untuk berbuat dalam situasi atau keadaan. Bohong adalah tidak sesuai dengan hal yang sebenarnya (KBBI 2005, 160).

Seperti dalam epsiode 34 pada menit ke 11:35, Gita dalam situasi merasa kasihan kepada Rizky melihat sahabatnya sedang berusaha keras medapatkan hati Nadine, namun rencana bisa gagal apabila Gita memberitahu sebenarnya. Maka agar Rizky tidak kecewa, yang dilakukan Gita adalah berbohong demi kebaikan Rizky.

Tindakan Antagonis Utama
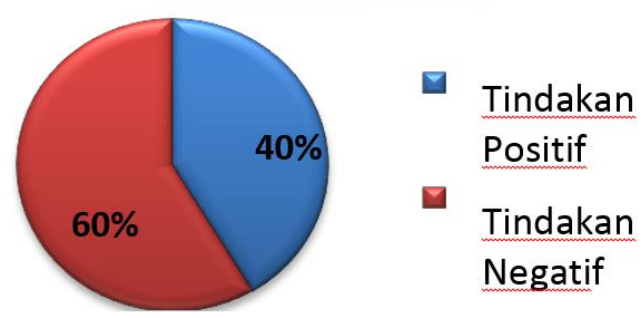

Gambar 3 Diagram lingkaran Tindakan Antagonis Utama

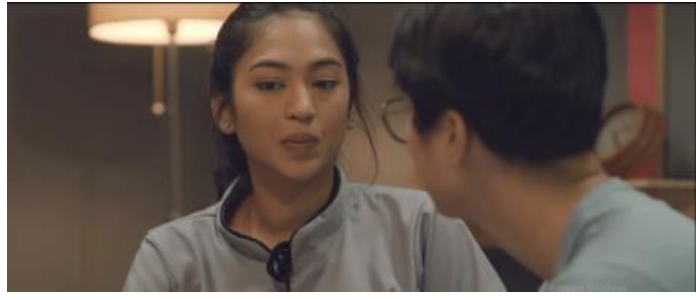

Gambar 4 Screen Shot eps. 34 Gita membohongi Rizky

Tindakan Berbohong dengan nilai negatif sebesar $0,13 \%$. Bentuk negatif yang dilakukan di episode 4, 13, 27 dan 51. Kebohongan yang memiliki nilai negatif seperti dalam episode 27 dan 51

Tindakan Gita membohongi pada tokoh utama selanjutnya pada episode 27 . Tindakan ini dilakukan karena Gita tidak ingin melihat kedekatan antara Nadine dan Rizky. Screen Shot 1 yaitu Nadine mengajak Rizky dan Gita untuk bertemu. Cara untuk menghindar dengan berbohong terlihat pada Screen Shot 2, Gita berbohong dengan Rizky dan Nadine bahwa dia sedang ada pekerjaan mendadak.

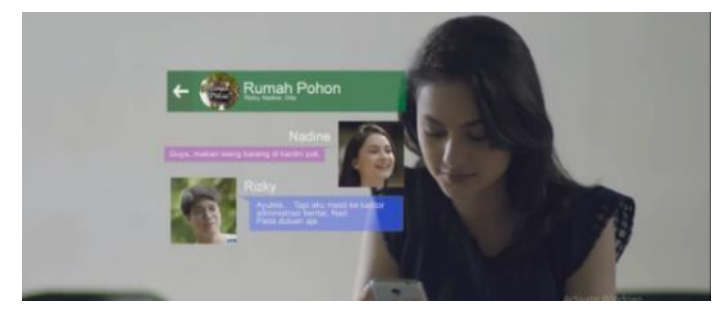

Gambar 5 Screen Shot 1 Episode 27, 33:09

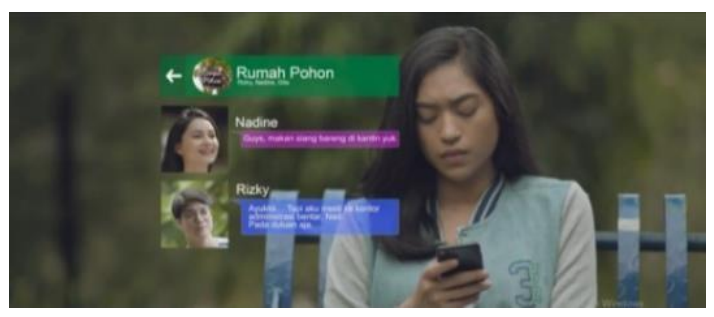

Gambar 6 Screen Shot 2 Episode 27, 33:14 
Inmas JakfarAbdillah, Siti Maemunah, Raden Roro Ari Prasetyowati,

Dengan data yang didapat, bahwa tindakan negatif dan positif dilakukan Gita sesuai dengan logika cerita. Tokoh Antagonis utama dalam sinetron "Cinta dan Rahasia seoason 1" Menempatkan pilihan dorongan untuk bertindak terhadap protagonis dengan mempertimbangan kondisi, alasan dan tujuan yang akan dilakukan. Tindakan yang paling banyak dilakukan oleh karakter antagonis utama yaitu Gita lebih banyak melakukan nilai negatif. Tindakan nilai positif juga dilakukan bahkan jumlah banyaknya tidak terlalu jauh dari nilai negatif.

Tindakan positif yang dilakukan Gita adalah pembuktian kelogisan dalam bertindak kepada tokoh protagonis. Seperti tindakan berbohong yang dilakukan Gita, berbohong agar rahasianya tidak terbongkar oleh Rizy dan Nadine. Karena rahasia ini apabila terbongkar akan mengakibatkan hubungan persahabatan mereka rusak. Pilihan tindakan Gita, untuk tidak memperparah keadaan hubungan persahabatan mereka adalah dengan berbohong. Setelah mengetahui dari alasan dan tujuan Gita dalam bertindak, dapat memungkinkan melakukan tindakan nilai positif. Walaupun posisi Gita sebagai karakter antagonis namun sisi positif tetap dilakukan, sesuai dengan kenaturalan fungsi sebuah karakter dalam narasi. Maksud dari kenaturalan fungsi adalah tindakan Gita sebagai karakter antagonis, tidak dibuat dengan melebihlebihkan sikap terhadap protagonis, agar menciptakan ketegangan dan konflik. Apabila sikap tersebut dibuat dilebihlebihkan, dapat memunculkan tindakan seperti merusak hubungan Rizky dan Nadine atau menganiaya karaker protagonis. Sikap dengan nilai positif juga dapat dilakukan seperti Gita lebih baik memendam rasa sakitnya agar tidak diketahui oleh karakter protagonis. Sikap ini juga mengahasilkan sebuah konflik dan drama yang menarik.

Tindakan karakter Gita banyak melakukan tindakan negatif, namun tindakan positif juga sangat signifikan sebesar 37\%. Jumlah ini dapat menunjukan bahwa karakter antagonis tidak selamanya menunjukan sisi negatifnya saja, layaknya sebagai manusia dalam suatu kehidupan dalam cerita, memiliki sisi yang positif. Hal ini dapat membuktikan bagaimana kelogisan cerita dapat dilihat dari hubungan dan tindakan yang dilakukan oleh karakterkarakter.

\section{Kesimpulan}

Hasil penelitian mengacu pada fokus permasalahan yang ada, dengan melihat pada pendekatan teori dan implementasinya pada ojek penelitian. Disimpulkan bahwa fungsi karakter antagonis utama yaitu Gita ditemukan 
sebanyak 13 Fungsi tindakan menurut teori Vladimir Propp, pada sinetron "Cinta dan Rahasia season 1". Adapun penjelasannya sebagai berikut :

1. $\operatorname{Kekerasan}(\delta)=$ Gita menyalahkan dan marah saat mengetahui bahwa Nadine Juga menyukai Rizky

2. Pengintaian $(\mathrm{E})=$ Gita membuat sebuah upaya pengintaian terhadap Rizky dan Nadine untuk mendapatkan informasi kedekatan mereka.

3. Pengiriman (C) = Gita selalu mendapatkan informasi yang membuat dirinya menjadi sedih dan kecewa terhadap Rizky dan Nadine.

4. Tipu daya $(\eta)=$ Gita membohongi Rizky dan Nadine tentang rahasianya agar hubungan persahabatanya tetap terjaga.

5. Keterlibatan $(\Theta)=$ Gita berhasil menipu Nadine dan Rizky. Tanpa sadar mereka masuk kedalam perangkap Gita.

\section{Kejahatan/ Kekuranagan} $(\mathrm{A})=\quad$ Perasaan marah Gita membuat dirinya bertindak menyalahkan dan mendoakan kejelakan kepada Rizky.

7. Mediasi (B) = Gita menolak permintaan maaf Rizky karena kesalahanya sangat besar.
8. Tindakan balasan $(\mathrm{C})=$ Gita memaafkan kesalahan Rizky, apabila Rizky dapat berusaha meluluhkan hatinya.

9. Perjuangan $(\mathrm{H})=$

Ketika Gita dan Rizky dengan keadaan sama-sama emosi mereka hanya beradu mulut.

10. Kemenangan $(\mathrm{I})=$ Gita lebih memilih menghindar dari Rizky dan Nadine.

11. Pengejaran $(\operatorname{Pr})=$ Gita berencana jujur untuk mengutarakan perasaanya sampai mendatangi rumah Rizky.

12. Pemaparan $($ Ex $)=$ Rahasia Gita terbongkar, diketahui oleh Rizky dan Nadine. Gita berusaha menutupi rahasianya dengan berbohong.

13. Hukuman $(\mathrm{U})=$ Gita merubah sikap menjadi negatif terhadap dan Rizky dan Nadine.

Fungsi karakter antagonis utama melakukan sebuah tindakan melalui hubungan karakter tersebut dengan tokoh protagonis. Tindakan tersebut mempunyai alasan dan tujuan yang mendorong untuk berbuat. Fungsi ini dapat menjadi salah satu penentuan kualitas pembuatan karakter tokoh utama dalam narasi. Pembuatan tokoh antagonis utama pada Gita dibuat sesuai logika dalam keadaan yang terjadi di cerita "Cinta dan Rahasia season 1". 
Inmas JakfarAbdillah, Siti Maemunah, Raden Roro Ari Prasetyowati,

Bukti kelogisan karakter antagonis utama dan untuk menyimpulkan rumusan masalah kedua, dapat ditemukan bahwa tindakan dilakukan mengandung nilai negatif dan juga positif. Tindakan negatif lebih banyak dilakukan namun tindakan positif juga hampir sama banyaknya. Tindakan negatif sebesar $58 \%$ dan tindakan positif sebesar $37 \%$. Tindakan positif sangat signifikan menunjukan bahwa karakter antagonis tidak selamanya hanya menunjukan sisi negatifnya, namun seperti halnya karakter manusia yang memiliki sisi positif juga perlu ditunjukan.

Dalam kaitan dengan cerita yang sedang diteliti, maksud dari tindakan negatif memiliki ciri merugikan. Gita melakukan tindakan negatif terhadap tokoh utama yatu Rizky dan Nadine. Tindakan ini mengakibatkan keadaan semakin kacau. Gita melakukan tindakan positif memiliki nilai menguntungkan, dengan tujuan memperbaiki keadaan menjadi baik karena sebelumnya sedang kacau. Hal ini juga membuktikan bahwa karakter antagonis tidak selamanya harus melakukan tindakan negatif saja, namun dilihat dari hubungan yang sedang dilakukan dengan tokoh lain. Pilihan tindakan yang dilakukan menyesuaikan kelogisan jalan cerita dari alasan dan tujuan.

\section{DAFTAR PUSTAKA}

Akbar, Budiman. Semua Bisa Menulis Skenario Panduan teknik menulis skenario untuk film dan sinetron. Jakarta: Erlangga, 2015

Boggs, M. Joseph, terj. The Art of Watching Film. Jakarta:Yayasan Citra, 2005

Eriyanto. ANALISIS NARATIF: Dasardasar dan Penerapannya dalam Analisis Teks Berita Media. Jarata: Prenadamedia GROUP, 2013

Fachruddin, Andi. Cara Kreatif Memproduksi Progam Televisi. Yogyakarta : Kencana, 2015

Lutters, Elizabet. Kunci Sukses Menulis Skenario, Jakarta: Grasindo, 2010.

Morisan, M.A. Jurnalistik Televisi Mutakhir. Jakarta: Kencana Prenada Media Group, 2008.

Paramita, Suryana, dan RB Armanto. SKENARIO Teknik Penulisan Struktur Cerita Film. Jakarta: Fakultas Film dan Televisi Institut Kesenian Jakarta, 2013

Saptaria, Rikrik El. Panduan Praktis Akting Untuk Film \& Teatater ACTING Handbook. Bandung: Rekayasa Sains Bandung, 2016

Setiawan, Nugraha. Penentuan Ukuran Sampel Memakai Rumus Slovin dan Tabel Krejcie-Morgan: Telaah Konsep dan Aplikasinya. Bandung: Universitas Padjajaran, 2007

Stanton, Robert, terj. An Introduction to Fiction. New York: Holt Rinehart and Winston, 1965

Sugiyono. Metode Penelitian Pendidikan Pendekatan Kuantitatif, 
Kualitatif, dan $R \& D$. Bandung: Alfabeta, 2014

Sutisno. Pedoman Praktis Penulisan Skenario Televisi dan Video. Yogyakarta: Diva Press, 2005.

Suwason, A.A. PENGANTAR FILM. Yogyakarta: ISI Yogyakarta, 2014

Tim Penyusunan Kamus Pusat Bahsa. KAMUS UMUM BAHASA INDONESIA. Jakarta: PT. Balai Pustaka, 2005

Walgito, Bimo. Pengantar Psikologi Umum.Yogyakarta: ANDI, 2001

Walgito, Bimo. Pengantar Psikologi Umum.Yogyakarta: ANDI, 2005

Wibowo. Semiotika Komunikasi Aplikasi Praktis Bagi Penelitian dan Skripsi Komunikasi. Jakarta: Mitra Wacana Media, 2011

\section{Media Online:}

http://www.netmedia.co.id diakses pada 01 Maret 2018, 16.50 WIB

https:// wordpress.com diakses pada 05 Maret 2018, 21.00 WIB

https://zulu.id diakses pada 29 Januari 2018, 17.00 WIB

\section{Daftar Sumber Karya:}

Hakim, Zainuddin. Morfologi Cerita Ratu Ular: Model Analisis Vladimir Propp (Morphology Of Ratu Ular Folklore: Vladimir Propp Analysis Model). Balai Bahasa Provinsi Sulawesi Selatan dan Provinsi Sulawesi Barat. Makasar. 2015

Nabila, Nella. Analısis Tokoh Dan Penokohan Dalam Film Иван Грозный 1-2 Я Серия/Ivan Groznyj 1-2 Ja Serijal Ivan yang Mengerikan Baglan 1-2 (1944-
1945) Karya Sergeı Mikhallovich Elsensteın. Fakultas Ilmu Budaya Universitas Indonesia. Depok. 2011

\section{Daftar Narasumber:}
Nama : Dewi Pramita
Umur : $\quad$ 26 Tahun
Pekerjaan : Script Writer drama serial PH LimeLight Picture

Kontak

1. Email : dewieyen@gmail.com

2. Ig:@dewieyen

3. http://dewieyen.blogspot.co.id/

4. www.wattpad.com/story/139585285kirana 